\title{
Subtropik koşullarda muzlarda takipçi bitki seçimine yeni bir yaklaşım
}

\author{
New approach for selecting follow sucker in subtropical conditions
}

\author{
Recep BALKIÇ, Lokman ALTINKAYA, Hamide GÜBBÜK, İlhami TOZLU \\ Akdeniz Üniversitesi, Ziraat Fakültesi, Bahçe Bitkileri Bölümü, Kampüs, 07058, Antalya \\ Sorumlu yazar (Corresponding author): H. Gübbük, e-posta (e-mail): gubbuk@akdeniz.edu.tr \\ Yazar(lar) e-posta (Authore-mail): recepbalkic@hotmail.com, lokmanaltinkaya@ hotmail.com, itozlu@akdeniz.edu.tr
}

\section{MAKALE BİLGİSİ}

Alınıs tarihi 01 Ocak 2018

Düzeltilme tarihi 14 Mart 2018

Kabul tarihi 23 Temmuz 2018

\section{Anahtar Kelimeler:}

Açıkta yetiştiricilik

Takipçi bitki

Yavru bitki seçim zamanı

Verim

Kalite

\begin{abstract}
ÖZ
Muz yetiştiriciliğinde bir sonraki ana bitkinin devamını sağlayacak yavru bitkinin seçimi (takipçi bitki), verim ve kaliteyi doğrudan etkilemektedir. Eğer yavru bitki ayarlanması düzenli olarak yapılmaz ise istenmeyen yavru bitkiler, ürün verecek yavru bitkilerin gübre ve suyu ile rekabete girmektedirler. $\mathrm{Bu}$ durum, ana bitkilerin gelişimlerini olumsuz yönde etkileyerek, verim ve kaliteyi düşürmektedir. Türkiye'de, yavru bitki ayarlamasında bir standart bulunmamaktadır. Planlanan bu çalışmada, farklı yavru bitki ayarlama sistemlerinin, muz yetiştiriciliğinde bazı morfolojik özellikler, verim ve kalite parametreleri üzerine etkileri araştırılmıştır. Araştırma, Gazipaşa-Antalya'da, açıkta yetiştiricilik koşullarında yapılmıştır. Çalışmada üretici koşulları-kontrol (Uygulama a), haziran ayının ilk haftasında gelişmesini tamamlamıs 5 (Uygulama b), 6 (Uygulama c) ve 7 yapraklı (Uygulama d) olmak üzere, dört farklı yöntem karşılaştırılmıştır. Sonuçlar, uygulama b ve c'nin, verim ve kalite parametrelerine bakımından en iyi sonucu verdiğini göstermiş ve pratikte bu iki uygulama tavsiye edilmiştir.
\end{abstract}

\section{ARTICLE INFO}

Received 01 January 2018

Received in revised form 14 March 2018

Accepted 23 July 2018

Keywords:

Open-field

Follow sucker

Sucker selection time

Yield

Quality

\begin{abstract}
In banana production, the sucker selected to replace the parent plant (follow sucker) are affected directly yield and quality. If this is not done properly, unwanted suckers can compete with crop suckers for fertilizer and irrigation. These results in poorer development of mother plants that end up with smaller bunch weight, low yield and quality. There is no standard treatment sucker management of banana in Turkey. The objectives of the study were to evaluate different sucker management systems for yield and quality enhancement of banana. The experiment was conducted under open-field conditions in Gazipaşa-Antalya. In this study four different management conditions were compared; Control-common farmer management system (Treatment a), selection of sucker for the following crop with 5 (Treatment b), 6 (Treatments c) and 7 (Treatment d) fully matured leaves in first week of the June. Best results for yield and quality parameters were obtained from treatment $\mathrm{b}$ and $\mathrm{c}$ and both treatments suggested to apply in the practical use.
\end{abstract}

\section{Giriş}

Muz, dünyada yaygın olarak ekvatorun $20^{\circ}$ kuzey ve güney enlemleri arasında kalan tropik iklim kuşağında yetiştirilmektedir. Ekvatorun $30^{\circ}$ kuzey ve güney enlemleri arasında ise yetiştiricilik subtropik iklim kuşağ 1 olarak adlandırılmaktadır (Stover ve Simmonds 1987). Subtropik koşullarda muz yetiştiren ülkelere Misır, İspanya, Güney Afrika, Lübnan, Portekiz, Türkiye, Fas, Ürdün ve İsrail örnek olarak gösterilebilir. Türkiye'de ise muz yetiştiriciliği enlem derecesi olarak subtropik koşulların bile dıșında $\left(36^{\circ}\right.$ kuzey enlemi) kalmaktadır (Gübbük ve ark. 2010). Buna rağmen, ülkemizde uzun yıllardan bu yana muz, açık ve örtüaltında ekonomik olarak yetiştirilmektedir. Son yıllarda, özellikle örtüaltı yetiştiricilik alanlarında meydana gelen önemli artışlar, ülkemizi neredeyse muz üretiminin önemli bir kısmını kendi öz kaynaklarından karşlayabilecek bir konuma getirmiştir. Bu durum hiç şüphesiz, ithalattan kaynaklanan döviz kaybının önlenmesi açısından bir kazanç olarak düşünülebilir.

Muz konusunda, tropik koşullarda yürütülen araştırmaların sonuçlarını bire bir subtropik koşullara uygulamak mümkün gözükmemektedir. Örneğin; tropik koşularda sıcaklık yıl boyu üretime olanak sağlarken, ülkemiz gibi subtropik koşullarda ise yıl boyu üretim sinırlı da olsa sadece örtüaltında yapılabilmektedir. Açıkta yetiştiricilikte ise üretim ağılıklı olarak kasım-şubat ayları arasında yoğunluk kazanmıştır. Ülkemizde açıkta yetiştiricilikte, muzlarda hevenk oluşumu 
genellikle temmuz ayında başlamakta ve ağustos ayının sonuna kadar devam etmektedir. Derim ise genellikle hevenk oluşumundan yaklaşı 140-150 gün sonra yapılmaktadır (Gübbük ve ark. 2010). Örtüaltında ise hevenk oluşumu ağırlıklı olarak haziran ayında başlamakta, temmuz ve ağustos ayları içerisinde tamamlanmaktadır. Son yıllarda bazı üreticiler, örtüaltı muz yetiştiriciliğinde y1l boyu üretim yaparak, özellikle yaz aylarında iç piyasa üretiminin sınırlı olduğu zamanlarda yüksek fiyat avantajından yararlanmaktadırlar. Açık ve örtüaltı muz yetiştiriciliğinde, hevenk oluşumunun yaz aylarının dışına kayması, meyve verim ve kalitesini düşürmekte ve ayrıca meyve gelişme süresini uzatmaktadır. Bu nedenle, takipçi bitkilerin özellikle subtropik koşullarda ne zaman bırakılacağının belirlenmesi, verim ve kaliteyi direkt olarak etkilemesi nedeniyle büyüm önem arz etmektedir.

Muzda yetiştiriciliğinde, ana bitkinin rizomları üzerinden dar ve geniş yapraklı olmak üzere iki farklı yaprak yapısına sahip takipçi bitkiler oluşmaktadır. Bu takipçi bitkilerden, ana bitkinin devamını sağlayacak olanların kılıç yapraklı olarak seçilmesine dikkat edilmektedir. Bu konuda uzun yıllardır edindiğimiz izlenimler, kılıç yapraklı yavru bitkilerin, geniş yapraklılara göre rizomun daha derin noktasından çıktığını ve hevenk ağırlığının daha yüksek olduğunu göstermiştir. Bu nedenle, dünyada olduğu gibi ülkemizde de ana bitkilerin devamını sağlayacak takipçi bitkiler, kılıç yapraklı olanlardan seçilmektedir.

Muz bitkisi, vejetasyon süresi boyunca çok sayıda yavru bitki oluşturmaktadır. Bu yavru bitkilerden ise sadece bir adedi ana bitkinin devamını sağlamak amacı ile takipçi olarak seçilmekte ve diğer yavru bitkiler ise ana bitkiden bir alet ya da kimyasal uygulamalar ile uzaklaştırılmaktadır. İstenmeyen yavru bitkilerin, ana bitkiden ne sıklıkta uzaklaştırılacağı, yetiştiriciliğin tropik ya da subtropik koşullarda yapılması ve işçilik maliyetine göre değişiklik göstermektedir. Robinson ve Galán Saúco (2010), subtropik koşullarda kış süresince büyümenin yavaş olması nedeniyle, ilkbahara kadar istenmeyen yavru bitkilerin ana bitkiden uzaklaştırılmasına ihtiyaç olmadığını, buna karşın subtropik ve tropik koşullarda yaz aylarında 3-4 hafta, ilkbahar ve sonbahar aylarında ise 6-8 hafta da bir ihtiyaç duyulduğunu saptamışlardır. Araştırıcılar ayrıca Avusturalya gibi işçiliğin çok yüksek olduğu ülkelerde ise yılda iki defa yapıldığını kaydetmişlerdir.

Ana bitki üzerinde, takipçi dişında yavru bitkilerin bırakılması, ana bitkiye besin maddesi akışını ve ayrıca ana bitkiye gidecek su miktarını olumsuz yönde etkileyerek verimi düşürmektedir (Oluwafemi 2013). Conie ve Young (2003), muzda istenmeyen yavru bitkiler uzaklaştırılmadığı zaman, ana bitkiye daha az besin maddesi gideceğini ve buna bağlı olarak hevenk ağırlığının düşeceğini ve ayrıca meyve gelişme süresinin uzayacağını bildirmişlerdir. Araştırıcılar, ayrıca aşırı nemin etkisi ile hastalıkların ve dolayısıyla birim alana düşen üretim maliyetinin de artacağını bildirmişlerdir. Mahdi ve ark. (2014), Sudan'da yürüttükleri çalışmada, muzda ana bitki ile birlikte bırakılan takipçi bitki sayısının büyüme ve verim üzerine etkilerini araştırmışlardır. Araştırıcılar, kontrol dışında (hiçbir işlem uygulanmamış), takipçi bitki sayısı açısından 3 farklı uygulamanın ( 1 ana bitki +1 yavru bitki, bir ana bitki +3 yavru bitki ve 1 ana bitki ve 4 yavru bitki) etkisini araştırmışlardır. Araştırıcılar, takipçi bitki sayısı arttıkça büyüme ve verim parametrelerine ait değerlerin düştüğünü bildirmişlerdir. Araştırma sonucunda, takipçi bitki sayısının azaltılmasının tarak sayısı ve meyve iriliğini arttırdığı belirlenmiştir. Ana bitki üzerinde bırakılan takipçi bitki sayısı yanında, takipçi bitkilerin büyümenin erken ya da geç aşamasında ana bitkiden bir alet ya da kimyasal yolla uzaklaştırılması da büyüme ve gelişme ile verim ve kaliteyi etkilemektedir. Bu konuda, Gasim ve ark. (2014) tarafindan yürütülen bir çalışmada, takipçi bitki dışında ana bitki üzerinde çıkan yavru bitkilerin farklı boya ulaştıktan sonra $(15,20,30$, $40,100 \mathrm{~cm}$ ) uzaklaştırılmasının, fonksiyonel yaprak sayısı, bitki boyu, derim zamanında gövde çapı ve meyve gelişme süresi üzerine etkileri araştırılmıştır. Araştırıcılar, takipçi bitki dışında kalan yavru bitkilerin ana bitkiden 15 ve $20 \mathrm{~cm}$ boya ulaştıktan sonra uzaklaştırılmasının, incelenen özellikler açısından 30, 40 ve $100 \mathrm{~cm}$ boya ulaştıktan sonra uzaklaştırılanlara göre daha iyi sonuç verdiğini bildirmiş̧lerdir. Araştırma sonucunda, takipçi bitki dışında kalan yavru bitkilerin, erken dönemde (15-20 cm boya ulaştı̆̆ zaman) ana bitkiden uzaklaştırılması tavsiye edilmiştir. Robinson and Nel (1990), Cavendish alt grubuna giren türlerde, istenmeyen yavru bitkilerin farklı boya (30, 50 ve $80 \mathrm{~cm}$ ) geldikten sonra ana bitkiden uzaklaştırılmasının verim üzerine etkisini araştırmışlardır. Araştırıcılar, 3 yıl süresince yürüttükleri çalışmada, istenmeyen yavru bitkilerin $50 \mathrm{~cm}$ ya da $80 \mathrm{~cm}$ boya geldiği zaman uzaklaștırılmasının, yıllık verimi \% 7.6 ve \% 15.6 oranında düşürdüğünü bildirmişler ve yavru bitkilerin $30 \mathrm{~cm}$ boya geldiği zaman ana bitkiden uzaklaştırılmasını tavsiye etmişlerdir.

Türkiye gibi subtropik iklim koşullarında muz yetiştiriciliği yapan Kanarya Adaları ve İsrail'de, yavru bitkilerin ayarlanması ile ilgili yöntemin bir birine benzediği bildirilmiştir (Robinson ve Galán Saúco 2010). Kanarya Adaları'nda, ana bitki ile rekabet etmemesi için takipçi dışında kalan yavru bitkiler $30 \mathrm{~cm}$ boya ulaşınca ana bitkiden alet yardımı ile uzaklaştırılmakta ve takipçi bitki seçimi ilkbaharda yaprak sayına göre yapılmaktadır. Her iki ülkede takipçi olarak haziran ayının altınc1 gününde 5 yaprağa sahip yavru bitkiler (5 yaprak/6. ayın/6. gününde) takipçi olarak bırakılmaktadır. Ülkemizde ise yavru bitki ayarlamada, zaman ve yavru bitki açısından bir standart bulunmamaktadır. Açıkta yetiştiricilikte, genellikle ana bitkinin etrafindan çıkan yavru bitkiler, mayıs ayına kadar ana bitkiden uzaklaştırılmakta ve mayıs ayından sonra çıkan yavru bitkilerden ise gelecek y1lın takipçileri seçilmektedir. Mayıs ayından sonra yapılacak takipçi bitki seçimlerinde ise her bir ana bitki için sadece bir ya da birden fazla takipçi bitki bırakılmaktadır. Sadece bir takipçi bitki seçildiği zaman, takipçi bitkiler zaman zaman çok hızlı büyüme ve gelişme göstererek gelecek yıl çok erken hevenk oluşturmaktadır (mayıs-haziran ayları). Erken oluşan hevenklerde, ağırlık ve meyve kalitesi, temmuz ve ağustos ayında hevenk oluşturan takipçilere göre daha düşük olmaktadır. Bu nedenle ülkemizde, her bir ana bitki için zaman zaman birden fazla takipçi bitki bırakılmaktadır. $\mathrm{Bu}$ durum ise bitki besin maddelerinin kullanımı ve su tüketimi açısından takipçilerin ana bitki ile rekabete girmesine neden olmaktadır. Yetiştiricilikte, her ana bitki için tek bir takipçi bırakmak ve bırakılan takipçilerin temmuz ve ağustos aylarında hevenk oluşturabilmesi için kaç gerçek yaprağa sahip olması gerektiği konusunun açıklığa kavuşturulması gerekmektedir. Bu nedenlerle planlanan bu araştırmada, haziran ayının ilk haftasında farklı gerçek yaprağa sahip takipçilerin bırakılmasının, subtropik koşullarda açıkta muz yetiştiriciliğinde bitkilerin bazı morfolojik ve fenolojik özellikler ile verim ve bazı kalite kriterleri üzerine etkilerinin ortaya konması amaçlanmıştır. 


\section{Materyal ve Yöntem}

$\mathrm{Bu}$ araştırma, 2013 ve 2014 yılları arasında Antalya'nın Gazipaşa (36 33' enlem derecesinde) ilçesinde açıkta yetiştiricilik yapılan bir bahçede yürütülmüştür. Denemenin yürütüldüğü lokasyonda, sıcaklık ve oransal nem günlük olarak saat başı HOBO cihazı ile kaydedilmiş ve değerler ortalama olarak verilmiştir. Değerlere göre; ortalama aylık sicaklık sadece aralık ve mart ayları arasından $14{ }^{\circ} \mathrm{C}$ 'nin (yaklaşık 12$13{ }^{\circ} \mathrm{C}$ ) altında ve diğer tüm aylarda ise $15^{\circ} \mathrm{C}$ 'nin üzerinde, ortalama yıllık oransal nem ise \% 60'ın üzerinde saptanmıştır. Araştırmada, çeşit olarak 'Dwarf Cavendish' kullanılmıştır. Araştırmanın yürütüldüğü lokasyonda, toprak yapısı tınlı, topraktaki organik madde düzeyi $\% 1.3$ ve $\mathrm{pH}$ ise 7.8 olarak kaydedilmiştir. Damla sulama sisteminin kullanıldığı çalışmada, y1llık bitki başına $200 \mathrm{~g}$ azot $\left(\mathrm{NH}_{4} \mathrm{SO}_{4}\right) 250 \mathrm{~g}$ fosfor (TSP) ve 1 $\mathrm{kg}$ potasyum $\left(\mathrm{KNO}_{3}\right)$ uygulanmıştır. Araştırmada, aşağıda belirtilen dört farklı uygulama denenmiştir.

-Uygulama a: Kontrol-üretici koşulları (mayıs ayı içerisinde ana bitkinin etrafinda çıkan kılıç yapraklı yavru bitkilerden bir adedinin takipçi olarak bırakılması ve daha sonra ortaya çıkan yavru bitkilerin genellikle ana bitkiden uzaklaştırılmaması)

-Uygulama b: Haziran ayının ilk haftasında ana bitkinin etrafında gelişen takipçilerden 5 yapraklı bir takipçi bırakılmış ve daha sonra çikan tüm takipçiler ana bitkiden uzaklaştırılmıştır.

-Uygulama c: Haziran ayının ilk haftasında ana bitkinin etrafında gelişen takipçilerden 6 yapraklı bir takipçi bırakılmış ve daha sonra çıkan tüm takipçiler ana bitkiden uzaklaştırılmıştır.

-Uygulama d: Haziran ayının ilk haftasında ana bitkinin etrafında gelişen takipçilerden 7 yapraklı bir takipçi bırakılmış ve daha sonra çıkan tüm takipçiler ana bitkiden uzaklaştırılmıştır.

Araştırmada, uygulamaların bitki morfolojik (gövde yüksekliği, gövde çevresi, toplam ve aktif yaprak sayısı), verim bileşenleri (tarak sayısı, parmak sayısı, hevenk ağırlığı) ve verim (gövde kesit alanına ve hektara verim) üzerine etkileri Gübbük ve ark. (2010)'na göre incelenmiştir. Hevenklerin derimi, parmaklarda köşeliliğin üçte iki oranında kaybolduğu zamanda yapılmış ve meyveler $16^{\circ} \mathrm{C}$ sicaklık ve $\% 90$ oransal nemde olgunlaştırılmıştır. Etilen uygulamasından sonra olgunlaşma periyodunda meyve kabuk rengindeki değişimler Minolta marka renk ölçme aleti ile $L^{*}, a^{*}$ ve $b^{*}$ değerleri cinsinden belirlenmiş ve kroma (C) ile hue $\left(\mathrm{h}^{\circ}\right)$ renk değerleri de aşağıdaki formüllere göre hesaplanmıştır.

$$
\begin{aligned}
& {[\mathrm{C}:(\mathrm{a} 2+\mathrm{b} 2),} \\
& \left.\mathrm{h}^{\circ}: \tan -1(\mathrm{~b} / \mathrm{a})\right]
\end{aligned}
$$

Rengin kırmızılığı ve sarılığını sayısal olarak ifade eden $\mathrm{h}^{\circ}$ değerinin azalması, rengin kırmızıya yaklaştı̆̆ını; artması ise kırmızıdan uzaklaştığını göstermektedir. C değeri ise rengin canlılığını ve matlığını sayısal olarak ifade ederken, sayının yüksek olması rengin daha canlı olduğunu göstermektedir.

Parmak ağırlığı, meyve kabuk kalınlığı, meyve eti sertliği, kabuk oranı ve SÇKM düzeyi ile kabuk rengi değişimi (C ve $\mathrm{h}^{\circ}$ ) olgunlaşmanın 6 no'lu aşamasında belirlenmiştir (Kader 2002).

Araştırma 3 yinelemeli ve her yinelemede, bitkisel özelliklere ilişkin ölçüm ve gözlemlerde 10 bitki ve pomolojik özelliklere ilişkin çalışmalarda ise 10 meyve kullanılmıştır.
Araştırma tesadüf parselleri deneme desenine göre planlanmış ve ortalamaların karşılaştırılmasında ise LSD testi (\%5) kullanılmıştır.

\section{Bulgular ve Tartışma}

Kontrol dahil tüm uygulamaların, incelenen kriterlerden gövde çevresi üzerine etkisi istatistiksel olarak önemsiz, gövde yüksekliği üzerine etkileri ise önemli bulunmuştur (Çizelge 1). Gövde yüksekliği, $120.83 \mathrm{~cm}$ ile 7 yapraklı olarak birakılan takipçilerde diğer uygulamalardan daha yüksek bulunmuştur. Uygulamaların, morfolojik özellikler üzerine etkileri istatistiksel olarak önemli bulunmuştur (Çizelge 2). Morfolojik özelliklerden toplam yaprak sayısı fide ayarlama zamanında 6 yapraklı olarak bırakılan (haziran ayının altısında 6 yaprakl1) takipçilerde daha yüksek belirlenmiştir. Aktif yaprak sayıs1 bakımından ise kontrol ile 5 ve 6 yapraklı olarak bırakılan takipçiler istatistiksel olarak aynı grup içerisinde yar almışlar ve en düşük aktif yaprak sayısı ise 7 yapraklı olarak bırakılan takipçi bitkilerde belirlenmiştir. Benzer şekilde, en düşük hevenk sap1 çevresi yine aktif yaprak sayısında olduğu gibi 7 yapraklı olarak bırakılan takipçi bitkilerde belirlenmiştir.

Çizelge 1. Uygulamaların gövde yüksekliği ve çevresi üzerine etkileri.

Table 1. Effect of treatments on pseudostem height and

\begin{tabular}{|c|c|c|}
\hline Uygulamalar & Gövde yüksekliği (cm) & Gövde çevresi $(\mathrm{cm})$ \\
\hline Kontrol & $104.88 c^{*}$ & 70.88 \\
\hline 5 Yapraklı & $114.00 \mathrm{~b}$ & 73.50 \\
\hline 6 Yapraklı & $108.91 \mathrm{bc}$ & 72.66 \\
\hline 7 Yapraklı & $120.83 \mathrm{a}$ & 70.66 \\
\hline $\mathrm{LSD} \% 5$ & 6.595 & Ö.D.** \\
\hline
\end{tabular}
circumference.

*LSD testine göre farklı harflerle gösterilen ortalamalar istatistiksel olarak birbirinden farklidır $(\mathrm{P} \leq 0.05)$

**Ö.D. istatistiksel olarak önemli değil.

Çizelge 2. Uygulamaların morfolojik özellikler üzerine etkileri.

Table 2. Effects of treatments on morphological features.

\begin{tabular}{lccc}
\hline Uygulamalar & $\begin{array}{c}\text { Toplam yaprak } \\
\text { sayısı (adet) }\end{array}$ & $\begin{array}{c}\text { Aktif yaprak } \\
\text { sayısı (adet) }\end{array}$ & $\begin{array}{c}\text { Hevenk sapı } \\
\text { çevresi (cm) }\end{array}$ \\
\hline Kontrol & $28.33 \mathrm{ab}^{*}$ & $13.66 \mathrm{a}$ & $22.83 \mathrm{a}$ \\
5 Yapraklı & $28.00 \mathrm{ab}$ & $13.50 \mathrm{a}$ & $21.83 \mathrm{ab}$ \\
6 Yaprakl1 & $29.33 \mathrm{a}$ & $14.17 \mathrm{a}$ & $22.91 \mathrm{a}$ \\
7 Yaprakl1 & $23.16 \mathrm{~b}$ & $10.33 \mathrm{~b}$ & $20.16 \mathrm{~b}$ \\
\hline LSD \% 5 & 5.551 & 3.158 & 2.347 \\
\hline
\end{tabular}

*LSD testine göre farklı harflerle gösterilen ortalamalar istatistiksel olarak birbirinden farklıdır. $(\mathrm{P} \leq 0.05)$.

Uygulamaların, verim bileşenleri üzerine etkilerine ilişkin bulgular Çizelge 3'de verilmiştir. Bu çizelgede görüldüğü üzere, uygulamaların verim bileşenleri üzerine etkisi istatistiksel olarak önemeli bulunmuştur. Tarak sayısı bakımından 2 ana grup oluşmuş, kontrol ile haziran ayının ilk haftasında 5 ve 6 yapraklı olarak bırakılan takipçiler aynı istatistiksel grup içerisinde yer almışlardır. Buna karşın, parmak sayısı bakımından istatistiksel olarak 3 ana ve bir ara grup oluşmuştur. En yüksek parmak sayısı 191.61 adet ile haziran ayının ilk haftasında 6 yapraklı olarak bırakılan takipçilerde ve en düşük ise 117.92 adet ile yine haziran ayının ilk haftasında 7 yapraklı olarak bırakılan takipçilerde belirlenmiştir. Parmak çevresi uygulamalara göre değişmekle birlikte $10.28 \mathrm{~cm}$ ile $12.28 \mathrm{~cm}$ ve parmak uzunluğu ise $21.39 \mathrm{~cm}$ ile $23.03 \mathrm{~cm}$ arasında saptanmıştır (Çizelge 3). Çizelge 3 'de de görüldüğü gibi gelecek yıl ana bitkilerin devamının sağlayacak takipçilerin 7 
yapraklı seçilmesi, tarak ve parmak sayılarında olduğu gibi parmak çevresi ve uzunluğu değerleri bakımından da en düşük değerleri vermiştir. $\mathrm{Bu}$ durum, hevenklerin erken dönemde (mayıs-haziran ayları) oluşumundan kaynaklanmıştır. Subtropik koşullarda açıkta yetiştiricilikte yüksek verim ve kalite için hevenk oluşumu, genellikle temmuz ve ağustos aylarının ortasında oluşması tercih edilmektedir.

Uygulamaların hevenk ağırlığı, gövde kesit alanına düşen verim ile hektara verim üzerine etkileri istatistiksel açıdan önemli bulunmuştur (Çizelge 4). En yüksek hevenk ağırlığı, 5 ve 6 yapraklı olarak bırakılan takipçilerde belirlenmiştir. Gövde kesit alanına ve hektara verim değerleri de hevenk ağırlığında olduğu gibi 5 ve 6 yapraklı olarak bırakılan takipçilerde daha yüksek kaydedilmiştir. Her üç özellik bakımından en düşük değerler ise 7 yapraklı olarak bırakılan takipçilerde belirlenmiştir. $\mathrm{Bu}$ durumun; 7 yapraklı olarak bırakılan takipçilerde, ana bitkinin henüz toplam sicaklık isteğini tam karşılamadan daha erken dönemde (mayıs ve haziran ayları) hevenk oluşturmasından kaynaklandığı düşünülmektedir. $\mathrm{Bu}$ aylarda oluşan hevenklerde, tarak sayısı, parmak sayısı ve dolayısıyla hevenk ağırlığının da düşük olması, her iki verim değeri üzerine olumsuz yönde yansımıştır.

Uygulamaların, olgunlaştırmadan sonra meyvelerin yeme olumunda saptanan pomolojik özellikleri üzerine etkileri Çizelge 5'de verilmiştir. Meyve eti sertliği dışında, uygulamaların incelenen tüm kriterler üzerine etkisi istatistiksel olarak önemli bulunmuştur. Parmak ağırlığı, 5 ve 6 yapraklı olarak bırakılan takipçilerde daha yüksek belirlenmiştir. En yüksek kabuk kalınlığı ve SÇKM oranı kontrol uygulamasında kaydedilmiştir. Tüketici açısından önemli bir kriter olan kabuk oranı, 7 yapraklı olarak bırakılan takipçi bitkilerde daha yüksek kaydedilmiştir (Çizelge 5).

Uygulamaların olgunlaştırma öncesi ve sonrası $\mathrm{C}$ ve $\mathrm{h}^{\circ}$ açı değerleri üzerine etkileri Çizelge 6'da verilmiştir. Uygulamaların, olgunlaştırma öncesi ve sonrası C değeri (parlaklık) üzerine etkisi istatistiksel olarak önemli bulunmuş ve olgunlaşma sonrası C değeri tüm uygulamalarda artış göstermiştir. Yeşil rengin sarıya dönüşümünü gösteren $\mathrm{h}^{\circ}$ açı değerleri, parlaklığın aksine tüm uygulamalarda düşüş göstermiştir.

Çizelge 3. Uygulamaların verim bileşenleri üzerine etkileri.

Table 3. Effects of treatments on yield components.

\begin{tabular}{lcccc}
\hline Uygulamalar & Tarak sayısı (adet) & Parmak sayısı (adet) & Parmak çevresi (cm) & Parmak uzunluğu (cm) \\
\hline Kontrol & $10.00 \mathrm{a}^{*}$ & $180.55 \mathrm{~b}$ & $12.10 \mathrm{a}$ & $21.70 \mathrm{~b}$ \\
5 Yapraklı & $10.33 \mathrm{a}$ & $185.82 \mathrm{ab}$ & $12.28 \mathrm{a}$ & $22.86 \mathrm{a}$ \\
6 Yaprakl1 & $10.58 \mathrm{a}$ & $191.61 \mathrm{a}$ & $12.25 \mathrm{a}$ & $23.03 \mathrm{a}$ \\
7 Yapraklı & $8.16 \mathrm{~b}$ & $117.92 \mathrm{c}$ & $10.28 \mathrm{~b}$ & $21.39 \mathrm{~b}$ \\
\hline LSD $\% 5$ & 1.713 & 6.810 & 0.599 & 0.715
\end{tabular}

*LSD testine göre farklı harflerle gösterilen ortalamalar istatistiksel olarak birbirinden farklıdır. ( $\mathrm{P} \leq 0.05)$.

Çizelge 4. Uygulamaların hevenk ağırlı̆̆ı ve verimler üzerine etkileri.

Table 4. Effects of treatments on bunch weight and yields.

\begin{tabular}{|c|c|c|c|}
\hline Uygulamalar & Hevenk ağırlığı (kg) & Gövde kesit alanına düşen verim $\left(\mathrm{g} \mathrm{cm}^{-2}\right)$ & $\operatorname{Verim}\left(\mathrm{t} \mathrm{ha}^{-1}\right)$ \\
\hline Kontrol & $19.76 \mathrm{~b}^{*}$ & $49.69 \mathrm{a}$ & $31.6 \mathrm{~b}$ \\
\hline 5 Yapraklı & $23.33 \mathrm{a}$ & $54.27 \mathrm{a}$ & $37.3 \mathrm{a}$ \\
\hline 6 Yapraklı & $23.53 \mathrm{a}$ & $55.98 \mathrm{a}$ & $37.6 \mathrm{a}$ \\
\hline 7 Yapraklı & $8.83 \mathrm{c}$ & $22.01 \mathrm{~b}$ & $14.1 \mathrm{c}$ \\
\hline LSD $\% 5$ & 0.628 & 9.929 & 0.109 \\
\hline
\end{tabular}

*LSD testine göre farklı harflerle gösterilen ortalamalar istatistiksel olarak birbirinden farklıdır ( $\mathrm{P} \leq 0.05)$.

Çizelge 5. Uygulamalarının pomolojik özellikler üzerine etkileri

Table 5. Effects of treatments on pomological features.

\begin{tabular}{|c|c|c|c|c|c|}
\hline Uygulamalar & Parmak ağırlığı (g) & Kabuk Kalınlığı (mm) & Meyve eti sertliği $\left(\mathrm{kg} \mathrm{cm}^{-2}\right)$ & Kabuk oranı (\%) & SÇKM (\%) \\
\hline Kontrol & $106.23 b^{*}$ & $3.09 \mathrm{a}$ & 1.54 & $39.38 \mathrm{~b}$ & $22.86 \mathrm{a}$ \\
\hline 5 Yapraklı & $122.80 \mathrm{a}$ & $2.91 \mathrm{ab}$ & 1.50 & $36.38 \mathrm{c}$ & $21.90 \mathrm{c}$ \\
\hline 6 Yapraklı & $119.64 \mathrm{a}$ & $2.71 \mathrm{~b}$ & 1.57 & $35.12 \mathrm{c}$ & $22.50 \mathrm{~b}$ \\
\hline 7 Yapraklı & $71.68 \mathrm{c}$ & $2.72 \mathrm{~b}$ & 1.49 & $44.55 \mathrm{a}$ & $21.90 \mathrm{c}$ \\
\hline $\mathrm{LSD}_{\% 5}$ & 3.244 & 0.340 & Ö.D.** & 2.448 & 0.171 \\
\hline
\end{tabular}

*LSD testine göre farklı harflerle gösterilen ortalamalar istatistiksel olarak birbirinden farklıdır $(\mathrm{P} \leq 0.05)$.

**Ö.D. istatistiksel olarak önemli değil.

Çizelge 6. Uygulamaların $\mathrm{C}$ ve $\mathrm{h}^{\circ}$ açı değerleri üzerine etkileri.

Table 6. Effects of treatments on $\mathrm{C}$ and $\mathrm{h}^{\circ}$ angle values.

\begin{tabular}{|c|c|c|c|c|}
\hline \multirow{2}{*}{ Uygulamalar } & \multicolumn{2}{|c|}{ Olgunlaştırmadan önce } & \multicolumn{2}{|c|}{ Olgunlaştırmadan sonra } \\
\hline & $\mathrm{C}$ & $\mathbf{h}^{\circ}$ & $\mathrm{C}$ & $\mathbf{h}^{\circ}$ \\
\hline Kontrol & $34.96 \mathrm{a}^{*}$ & $117.30 \mathrm{a}$ & $45.00 \mathrm{a}$ & 87.74 \\
\hline 5 Yapraklı & $32.95 \mathrm{~b}$ & $115.66 \mathrm{a}$ & $41.19 \mathrm{~b}$ & 87.33 \\
\hline 6 Yapraklı & $32.99 \mathrm{~b}$ & $113.78 \mathrm{~b}$ & $41.58 \mathrm{~b}$ & 87.54 \\
\hline 7 Yapraklı & $32.74 \mathrm{~b}$ & $113.24 \mathrm{~b}$ & $40.25 \mathrm{~b}$ & 86.50 \\
\hline $\mathrm{LSD}_{\% 5}$ & 0.911 & 1.706 & 1.484 & Ö.D. ${ }^{* *}$ \\
\hline
\end{tabular}

*LSD testine göre farklı harflerle gösterilen ortalamalar istatistiksel olarak birbirinden farklıdır $(\mathrm{P} \leq 0.05)$

**Ö.D. istatistiksel olarak önemli değil. 
Haziran ayının ilk haftasında 5 ve 6 gerçek yaprağa sahip takipçilerin bırakılması, morfolojik özellikler açısından en iyi sonucu vermiştir. Verim ve meyve pomolojik özellikleri açısından yine en iyi sonuçlar, morfolojik özelliklerde olduğu gibi haziran ayının ilk haftasında 5 ve 6 gerçek yaprağa sahip takipçilerden elde edilmiştir. Yedi gerçek yaprağa sahip takipçilerde ise bitkilerin daha erken hevenk oluşturması (mayıs ve haziran aylarında) nedeniyle, hevenk ağırlığ 1 ve buna bağlı olarak gövde kesit alanı ve hektara verim değerlerinde düşüşler kaydedilmiştir. Olgunlaşmadan sonra, albeni açısından önemli bir kriter olan sarı rengin dönüşümü bakımından uygulamalar arasında istatistiksel bir farklılık belirlenmemiştir. Kanarya Adaları ve İsrail'de, ticari yetiştiricilikte haziran ayının altıncı gününde, 5 yaprağa sahip yavru bitkilerin (5 yaprak/6.ayın/6. gününde) takipçi olarak bırakıldığ bildirilmiştir (Robinson ve Galán Saúco 2010). Çalışmamızda ise haziran ayının ilk haftasında 5 yaprağa sahip takipçiler yanında, 6 yaprağa sahip takipçilerin bırakılması da özellikle hevenk ağırlığı, gövde kesit alanına düşen verim ve hektara verim bakımından en iyi sonucu vermiştir. Bu durum, ekolojik koşulların farklılığından kaynaklanmış olabilir. Çalışmamızda, haziran ayının ilk haftasında takipçilerin 7 yapraklı olarak bırakılmasında verimin düşük olması, bitkilerin toplam sıcaklık isteğini tam karşılamadan daha erken hevenk oluşturması ve kontrol bitkilerinde daha düşük hevenk oluşturması ise Conie ve Young (2003) ile Mahdi ve ark. (2014)'ün çalışmalarında olduğu gibi kontrol uygulamasında, takipçi bitkilerin ana bitkilerle rekabete girerek, su ve bitki besin maddesi akışını olumsuz yönde etkilemesinden kaynaklanmış olabileceği düşünülmektedir.

\section{Sonuç}

Araştırma sonucunda, subtropik koşullarda açıkta muz yetiştiriciliğinde, verim ve kalite kriterleri açısından haziran ayının ilk haftasında 5 ve 6 gerçek yaprağa sahip takipçilerin bırakılması önerilmiştir.

\section{Teşekkür}

$\mathrm{Bu}$ araştırma, Alanya Ticaret Odası ve Akdeniz Üniversitesi Bilimsel Araştırma Projeleri Kordinasyon Birimi (Proje no: 2012.0104.001) tarafından desteklenmiştir.

\section{Kaynaklar}

Conie J, Young M (2003) Banana sucker pruning manual. Research Department, Banana Export Company (Jamaica), European Union Banana Support Programme. http://thebananaboard.org/pdf/Pruning.pdf.

Gasim S, Mahdi EFH, Ahmed FAR (2014) Effects of stage of desuckering on growth characteristics of banana clone Willimas W193/3. International Journal of Science, Environment and Technology 3(1): 357-364.

Gübbük H, Pekmezci M, Selli S, Erkan M, Kafkas E, Pinar H, Güven D, Güneş E (2010) Değişik lokasyonlarda açıkta ve örtüaltında yetiştirilen 'Dwarf Cavendish' muz çeşidinde verim, bazı kalite kriterleri ve aroma maddeleri ile meyvelerin derim sonrası özelliklerinin belirlenmesi üzerinde araştırmalar. TÜBİTAK, Proje No: 107O156. s. 247.

Kader AA (2002) Postharvest technology of horticultural crop. $3^{\text {rd }}$ Edition, Publication 3311. Division of Agriculture and Natural Resources, University of California, Oakland, California, USA.

Mahdi EFM, Bakhiet SB, Gasim S (2014) Growth and yield responses of banana plant to desuckering practice. International Journal of Science, Environment and Technology 3: 279-285.
Oluwafemi AB (2013) Influence of number of sucker per plant on the growth, yield and yield components of Plantain (Musa sp) in AdoEkiti, Nigeria. Agricultural Science Research Journal 3(2): 45-49.

Robinson JC, Nel DJ (1990) Competitive inhibition of yield potential in a 'Williams' banana plantation due to excessive sucker growth. Scientia Horticulturae 43: 225-236.

Robinson JC, Galán Saúco V (2010) Bananas and plantains. $2^{\text {rd }}$ Edition, Crop Production Science in Horticulture Series 19, Oxford, CAB International.

Stover RH, Simmonds NW (1987) Bananas. $3^{\text {rd }}$ Edition, Harlow, UK, Longman. 